Published in final edited form as:

Cochrane Database Syst Rev. ; 3: CD001835. doi:10.1002/14651858.CD001835.pub3.

\title{
Surgery for small asymptomatic abdominal aortic aneurysms
}

\author{
Giovanni Filardo ${ }^{1}$, Janet T Powell ${ }^{2}$, Melissa Ashley-Marie Martinez ${ }^{3}$, and David J Ballard ${ }^{1}$ \\ ${ }^{1}$ Institute for Health Care Research and Improvement, Baylor Health Care System, Dallas, Texas, \\ USA \\ ${ }^{2}$ Vascular Surgery Research Group, Imperial College London, London, UK \\ ${ }^{3}$ Health Policy and Management, University of North Carolina, Chapel Hill, North Carolina, USA
}

\begin{abstract}
Background-An abdominal aortic aneurysm (AAA) is an abnormal ballooning of the major abdominal artery. Some AAAs present as emergencies and require surgery; others remain asymptomatic. Treatment of asymptomatic AAAs depends on many factors but an important one is size of the aneurysm, as risk of rupture increases with aneurysm size. Large asymptomatic AAAs ( $>5.5 \mathrm{~cm}$ in diameter) are usually operated on; very small AAAs $(<4.0 \mathrm{~cm}$ diameter) are monitored with ultrasonography. The optimal timing of surgery would benefit from further evidence.
\end{abstract}

Objectives-This review compared long-term survival in patients with AAAs of diameter 4.0 to $5.5 \mathrm{~cm}$ who received immediate repair versus routine ultrasound surveillance.

Search methods-For this update the Cochrane Peripheral Vascular Diseases Group searched their Specialised Register (February 2012) and CENTRAL (2012, Issue 1). Reference lists of relevant articles were checked for additional studies and the searches were supplemented by handsearches of recent conference proceedings and information from experts in the field.

Selection criteria-Randomised controlled trials in which men and women with asymptomatic AAAs of diameter 4.0 to $5.5 \mathrm{~cm}$ were randomly allocated to immediate repair or imaging-based surveillance at least every six months. Outcomes had to include mortality or survival.

Data collection and analysis-Two authors (GF, MAMM) abstracted the data, which were cross-checked by the other authors (DJB, JTP). Due to the small number of trials, formal tests of heterogeneity and sensitivity analyses were not conducted.

Copyright (C) 2012 The Cochrane Collaboration.

Contact address: Giovanni Filardo, Institute for Health Care Research and Improvement, Baylor Health Care System, 8080 N. Central Expressway, Suite 500, Dallas, Texas, TX 75206, USA. GiovanFi@BaylorHealth.edu.

Editorial group: Cochrane Peripheral Vascular Diseases Group.

Publication status and date: New search for studies and content updated (no change to conclusions), published in Issue 3, 2012.

Review content assessed as up-to-date: 8 February 2012.

CONTRIBUTIONS OF AUTHORS

All authors identified trials and agreed on their inclusion or exclusion, adequacy of randomisation, attainment of adequate sample size, and completeness of follow up. For this update, two authors (GF and MAMM) abstracted the data, which were cross-checked by another two authors.

DECLARATIONS OF INTEREST

JTP was a co-investigator in the UKSAT study and DJB was a co-investigator of the ADAM trial. 
Main results-Four trials with a combined total of 3314 patients, the UK Small Aneurysm Trial (UKSAT), the Aneurysm Detection and Management (ADAM) trial, the Comparison of Surveillance Versus Aortic Endografting for Small Aneurysm Repair (CAESAR), and the Positive Impact of Endovascular Options for treating Aneurysms Early (PIVOTAL) fulfilled the inclusion criteria. The four trials showed an early survival benefit in the surveillance group (due to 30-day operative mortality with surgery) but no significant differences in long-term survival (adjusted hazard ratio (HR) $0.88,95 \%$ confidence interval (CI) 0.75 to 1.02 , mean follow up 10 years (UKSAT); HR 1.21, 95\% CI 0.95 to 1.54 , mean follow up 4.9 years (ADAM); HR 0.76, 95\% CI 0.30 to 1.93 , median follow up 32.4 months (CAESAR); HR 1.01, 95\% CI 0.49 to 2.07, mean follow up 20 months (PIVOTAL)). The meta analyses of mortality at one year (CAESAR and PIVOTAL only) and six years (UKSAT and ADAM only) revealed a non-significant association (Peto odds ratio at one year $1.15,95 \%$ CI 0.59 to 2.25 ; Peto odds ratio at six years $1.11,95 \%$ CI 0.91 to 1.34$)$.

Authors' conclusions-The results from the four trials to date demonstrate no advantage to early repair (via open or endovascular surgery) for small AAA $(4.0$ to $5.5 \mathrm{~cm}$ ) and suggest that 'best care' for these patients favours surveillance. Furthermore, the more recent trials focused on the efficacy of endovascular aneurysm repair and still failed to show benefit. Thus, both open and endovascular repair of small AAAs are not supported by currently available evidence.

\section{Medical Subject Headings (MeSH)}

Aortic Aneurysm, Abdominal [mortality; *surgery; ultrasonography]; Cost-Benefit Analysis; Organ Size; Quality of Life; Randomized Controlled Trials as Topic; Time Factors

\section{MeSH check words}

Female; Humans; Male

\section{BACKGROUND}

\section{Description of the condition}

An aneurysm is an abnormal dilatation of an artery. This can occur in any artery including the abdominal aorta, below the branches to the renal arteries (Ernst 1993; Stonebridge 1996). Abdominal aortic aneurysms (AAAs) are rare in people under 50 years of age, but thereafter prevalence increases sharply with increasing age (ADAM). AAAs occur in about $5 \%$ of men aged 65 to 74 years and are approximately three times more common in men than in women (ADAM). Low prevalence rates have been observed for African American males compared to Caucasian males and black race has been identified as having a strong negative association with AAA (ADAM).

The cause of AAA is likely to be multifactorial (Shah 1997). It may result from a change in the composition of the collagen and elastin matrix in the media of the arterial wall due to excessive proteolysis. AAAs often coincide with atherosclerosis in the aortic wall but it is not known if atherosclerosis is involved in the pathogenesis of aneurysms. Inflammation of the aortic wall also appears to be influential. The main well-established risk factor is cigarette smoking, with smokers having a two-to three-fold increased risk of AAA compared 
to non-smokers (ADAM; Lederle 2003). Aneurysms also occur more frequently in close relatives of patients who suffered an AAA, but a mode of inheritance has not been demonstrated (Ballard 1999).

The progression of AAA can vary considerably (Ernst 1993). Some people remain asymptomatic throughout life while others present with symptoms such as back pain or a pulsating abdominal mass; or as emergencies following rupture. The risk of rupture increases with aneurysm size and mortality following rupture is high (approximately 60\% die before reaching hospital) (Ballard 1999).

\section{Description of the intervention}

Ruptured AAAs require emergency surgical repair, which has a mortality rate of $40 \%$ to $50 \%$. The outcome of surgery is highly dependent on the patient's presenting features, including general clinical condition (Ernst 1993; Stonebridge 1996). Surgery for patients with symptomatic AAAs is considered necessary to relieve symptoms and to reduce the risk of rupture and death.

In the case of asymptomatic AAAs, however, management depends on the size of the aneurysm. To date, no medical therapy has been shown to reduce the rate of size change or risk of rupture among patients with asymptomatic AAAs (Ballard 1999; Ernst 1993; UKSAT); however, several studies are currently ongoing (personal communication JTP). Surgery is performed on larger aneurysms $(>5.5 \mathrm{~cm}$ in diameter) while very small aneurysms $(<4.0 \mathrm{~cm}$ in diameter), in which the risk of rupture is low, are monitored for growth through regular imaging, usually ultrasonography. For small AAAs ( 4.0 to $5.5 \mathrm{~cm}$ diameter) there has been considerable debate as to the most beneficial course of treatment; that is, immediate repair versus surveillance and selective repair of AAAs that subsequently enlarge (Lederle 1996). Much of this debate centres around the uncertainty of risk of rupture for small AAAs.

\section{How the intervention might work}

A literature review conducted by a RAND Corporation panel in 1991 assessed the appropriateness and necessity of surgery for AAAs and found reports of risk of rupture, based on referral case series, as high as 5\% per year for AAAs $>5.0 \mathrm{~cm}$ and of 3\% to 5\% per year for AAAs $5.0 \mathrm{~cm}$ (Ballard 1992), which supports arguments in favour of the aggressive approach of immediate repair. Population data, however, suggest that risk of rupture for AAAs < $5.0 \mathrm{~cm}$ is less than 1\% per year (Ballard 1992; Nevitt 1989), under which scenario the merits of selective surveillance are apparent. Similarly, population studies suggest that early reports of expansion rates of approximately $0.4 \mathrm{~cm} /$ year for AAAs between $4.0 \mathrm{~cm}$ and $6.0 \mathrm{~cm}$ in diameter (Bernstein 1984) had overestimated growth by approximately $0.2 \mathrm{~cm} /$ year (Nevitt 1989), inaccurately favouring aggressive intervention.

\section{Why it is important to do this review}

The 'grey area' of care for small AAAs, resulting from the uncertainty surrounding the risk of rupture versus the risk of intervention and expansion rates identified by the RAND panel, highlighted the need for randomised controlled trials comparing immediate surgery and 
selective surveillance as treatment options. This led to the design of the Aneurysm Detection and Management (ADAM) trial (ADAM), the United Kingdom Small Aneurysm Trial (UKSAT) (UKSAT), and the Canadian Trial, which used open surgery to perform the repairs. Later, when endovascular repair became available, the Comparison of Surveillance Versus Aortic Endografting for Small Aneurysm Repair (CAESAR) and the Positive Impact of Endovascular Options for treating Aneurysms Early (PIVOTAL) were conducted, using endovascular repair as the surgical option.

\section{OBJECTIVES}

To compare mortality, quality of life, and cost effectiveness of early or immediate surgical repair versus routine ultrasound surveillance in patients with asymptomatic AAAs between $4.0 \mathrm{~cm}$ and $5.5 \mathrm{~cm}$ in diameter.

\section{METHODS}

\section{Criteria for considering studies for this review}

Types of studies-Randomised controlled trials (RCTs) in which patients were randomly allocated to early or immediate surgery versus ultrasound surveillance.

Types of participants-Men or women of any age with an asymptomatic AAA. The aneurysm was restricted to the abdominal aorta distal to the renal arteries. The maximum antero-posterior diameter, measured using ultrasound or computerised tomography (CT) scanning, must have been at least $4.0 \mathrm{~cm}$ and less than $5.5 \mathrm{~cm}$. The aneurysm should have been non-tender on examination and the patient assessed as generally fit for surgery.

Types of interventions-Surgical repair of the aneurysm consisting of insertion of a prosthetic inlay graft either by open surgery (abdominal or retroperitoneal route) or by endovascular repair. Surveillance of the maximum antero-posterior diameter was to be performed regularly, with a maximum interval of six months.

\section{Types of outcome measures}

Primary outcomes: The outcome measures included at least one of the following:

- life expectancy, expected number of years of life remaining following randomisation;

- mortality, death rate during a specified period of time following randomisation;

- quality of life, a standard generic measure using a validated instrument encompassing typical domains such as pain, health perceptions, mental health, and physical and social functioning.

Secondary outcomes: The costs, from trial data, a specific survey, or routine statistics, which might have included:

- direct hospital costs, all hospital costs attributable to inpatient stays, surgery, and out-patient attendances including ultrasound surveillance; 
- other health service costs, non-hospital costs such as general practitioner attendances, ambulance transfers, convalescence;

- societal costs, non-health service costs to society such as loss of productivity, time off work, sickness benefit.

The following outcome measures were of interest but were not included in a meta-analysis because they were relevant to only one arm of a trial or were of doubtful validity:

- cause of death, mortality by underlying cause of death according to the International Classification of Diseases;

- operative mortality, measured as 30-day or 'in hospital' mortality;

- rupture, rate of aneurysm rupture diagnosed at postmortem, operation, or certified as the underlying cause of death.

\section{Search methods for identification of studies}

Electronic searches-For this update, the Cochrane Peripheral Vascular Diseases Group Trials Search Co-ordinator (TSC) searched the Specialised Register (February 2012) and the Cochrane Central Register of Controlled Trials (CENTRAL) (2012, Issue 1), part of The Cochrane Library (www.thecochranelibrary.com). See Appendix 1 for details of the search strategy used to search CENTRAL. The Specialised Register is maintained by the TSC and is constructed from weekly electronic searches of MEDLINE, EMBASE, CINAHL, AMED, and through handsearching relevant journals. The full list of the databases, journals, and conference proceedings which have been searched, as well as the search strategies used, are described in the Specialised Register section of the Cochrane Peripheral Vascular Diseases Group module in The Cochrane Library (www.thecochranelibrary.com).

Searching other resources-The reference lists of relevant studies were checked. The searches were supplemented by information from experts in the field and from handsearches of the following conference proceedings.

- The International Society for Vascular Surgery Congress (through to 2011).

- The Society for Vascualr Surgery Annual Meeting (through to 2011).

- The Society for Clinical Vascular Surgery Annual Symposium (through to 2011).

- The European Society for Vascular Surgery Annual Meeting (through to 2010).

\section{Data collection and analysis}

Selection of studies-The trials comparing surgical repair versus selective surveillance for small AAAs were identified by DJB, GF, MAMM, and JTP.

\section{Data extraction and management}

For the update, two authors (GF and MAMM) abstracted the data, which were crosschecked by the other authors (DJB and JTP). The data collected on each trial included information on the participants (age and sex distribution, aneurysm size), the interventions 
(graft type, frequency of ultrasound surveillance), and the outcomes (as specified in 'Criteria for considering studies for this review').

\section{Assessment of risk of bias in included studies}

The four authors discussed each of the trials and agreed on their inclusion or exclusion based on the adequacy of the random allocation, attainment of adequate sample size, and completeness of follow up. The nature of the interventions did not permit participants or observers to be blinded and so this lack did not disqualify trials from inclusion. In addition, the risk of bias of the included studies was assessed using the 'Risk of bias' tool as described in the Cochrane Handbook for Systematic Reviews of Interventions (Higgins 2011). The following domains were assessed and judged to be at low risk of bias, high risk of bias, or unclear risk of bias: selection bias, performance and detection bias, attrition bias, reporting bias, and other sources of bias.

\section{Measures of treatment effect}

Odds ratios (ORs) (30-day mortality) and hazard ratios (HRs) (long-term survival) were estimated to assess the efficacy of the intervention in each study.

\section{Unit of analysis issues}

Patients with AAAs of diameter 4.0 to $5.5 \mathrm{~cm}$ who received immediate surgical repair versus routine ultrasound surveillance.

\section{Dealing with missing data}

None of the studies included in this review used single or multiple imputation procedures to deal with missing data. However, the incidence of missing data was very low.

\section{Assessment of heterogeneity}

Due to the small number of trials, a qualitative presentation of the trial results is reported in the present review. Meta-analyses of mortality at one year and six years were performed. Heterogeneity was assessed using the $\mathrm{I}^{2}$ statistic. We considered values of $\mathrm{I}^{2}$ of $50 \%$ or greater to indicate substantial heterogeneity. Where heterogeneity was identified, reasons for it were explored.

\section{Assessment of reporting biases}

Given the qualitative nature of the present review, formal statistical tests were not carried out. However, all included studies published findings on the main study outcome of this review.

\section{Data synthesis}

Due to the small number of trials, the present review focused on a qualitative presentation of the trial results. However, fixed-effect model meta-analyses of mortality at one year and six years, estimating Peto ORs and 95\% confidence intervals (CIs), were also presented. 


\section{Subgroup analysis and investigation of heterogeneity}

Due to the small number of trials, a subgroup analysis was not carried out.

\section{Sensitivity analysis}

Due to the small number of trials, a sensitivity analysis was not carried out.

\section{RESULTS}

\section{Description of studies}

See: Characteristics of included studies; Characteristics of excluded studies.

\section{Results of the search}

Four relevant randomised controlled trials were identified from the electronic searches (ADAM; CAESAR; PIVOTAL; UKSAT) and one from personal communication (Canadian Trial).

\section{Included studies}

Four studies, the UKSAT (UKSAT), ADAM (ADAM), CAESAR (CAESAR), and PIVOTAL (PIVOTAL) trials, fulfilled the criteria for consideration in the present review. Patient inclusion and exclusion criteria for the studies were comparable. All the trials enrolled patients with small $(4.0$ to $5.5 \mathrm{~cm}$ ) non-tender, asymptomatic AAAs and who were considered to be fit for immediate surgery. The four trials excluded patients who were considered unfit for immediate surgery, had symptoms associated with the aneurysm, were unable to attend the follow-up visit, or were unable to give informed consent. The ADAM study further excluded patients who: received a revascularisation procedure within three months of enrolment, had a myocardial infarction within six months of enrolment, or were expected to survive less than five years because of invasive cancer or another lifethreatening disease. The CAESAR trial, besides excluding those patients not anatomically suitable for endovascular repair, further excluded patients who had severe comorbidities or a suprarenal or thoracic aorta $\geq 4.0 \mathrm{~cm}$ in diameter, or needed urgent repair. The PIVOTAL study further excluded patients who had an abdominal or thoracic repair, an aneurysm originating $\leq 1.0 \mathrm{~cm}$ from the most distal main renal artery, life expectancy of $<3$ years, Society for Vascular Surgery (SVS) score $>2$ with the exception of age and controlled hypertension, baseline serum creatinine level $>2.5 \mathrm{mg} / \mathrm{dL}$, or when the patient did not meet the indications for use of the endograft device.

Lastly, age inclusion criteria were 50 to 79 years, 50 to 79 years, 40 to 90 years, and 60 to 76 years for the ADAM, CAESAR, PIVOTAL and UKSAT studies, respectively. Despite the relatively wider age range eligible for inclusion in the ADAM, CAESAR, and PIVOTAL trials, the majority of the participants fell within the same age range as the UKSAT trial: $88 \%$, approximately $70 \%$, and approximately $70 \%$, respectively, which is perhaps unsurprising given that AAA prevalence is much higher in older age groups. In total, 3314 patients with asymptomatic AAAs of antero-posterior diameter 4.0 to $5.5 \mathrm{~cm}$ were randomised to immediate surgery $(n=1680: 569$ in ADAM, 182 in CAESAR, 366 in PIVOTAL, and 563 in UKSAT; 50.7\%) or routine ultrasound or computed tomography 
surveillance every six months (three months if diameter 5.0 to $5.5 \mathrm{~cm}$ in ADAM and UKSAT) ( $\mathrm{n}=1634: 567$ in ADAM, 178 in CAESAR, 362 in PIVOTAL, and 527 in UKSAT; $49.3 \%$ ). The primary outcome was all-cause mortality and secondary measures were AAA-related death, morbidity and quality of life. Follow up for vital status ranged from: 3.5 to 8.0 years (mean 4.9 years) in the ADAM trial, median 32.4 months (IQR 21.0 to 44.1 ) in the early endovascular repair group and 30.9 (IQR 18.3 to 45.3 ) in the surveillance group in CAESAR trial, $20 \pm 12$ months (range 0 to 41 months) in the PIVOTAL trial, and up to 12 years (range 8 to 12 years, mean 10 years) in the UKSAT trial. Approximately 95\% and $90 \%$ of patients were alive at one and two years after randomisation, respectively, in the ADAM and UKSAT trials. Thereafter, survival rates decreased more rapidly in the UKSAT study. The 5-year survival rate was approximately $70 \%$ in the UKSAT study and approximately $80 \%$ in the ADAM trial. The 12 -year survival rate was approximately $35 \%$ in the UKSAT trial. In the CAESAR trial there was no difference in the all-cause mortality of the immediate surgery and selective surveillance groups (hazard ratio (HR) $0.76,95 \% \mathrm{CI}$ 0.30 to $1.93, \mathrm{P}=0.6$ ) and at 54 months the cumulative probability of mortality was $14.5 \%$ in the early endovascular repair and $10.1 \%$ in the surveillance group, and aneurysm-related mortality was $<1 \%$ in both groups. In the PIVOTAL trial the overall mortality was $4.1 \%$ in both groups (HR $1.01,95 \% \mathrm{CI} 0.49$ to $2.07, \mathrm{P}=0.98$ ) and the aneurysm related mortality was $<1 \%$ in both groups.

\section{Excluded studies}

The trial that did not fulfil the criteria for consideration was the Canadian Trial, which ended early because of inadequate recruitment (Cole CW, personal communication, 1998) and was not sufficiently complete for inclusion in this review.

\section{Risk of bias in included studies}

The UKSAT, ADAM, CAESAR, and PIVOTAL are the trials to date which met the inclusion criteria. Study designs were similar with patients randomly allocated to either immediate surgery or selective surveillance. In the four trials most patients assigned to the immediate surgery group received endovascular or standard open repair within six weeks of randomisation. Likewise, in all four trials patients assigned to selective surveillance were followed, without repair, at regular intervals (at minimum once every six months) and surgery was performed within six weeks if: a) the aneurysm reached $5.5 \mathrm{~cm}$ in diameter; or b) the aneurysm enlarged by a minimum of $0.7 \mathrm{~cm}$ in six months (ADAM), $1.0 \mathrm{~cm}$ in one year (ADAM), greater than $1.0 \mathrm{~cm}$ in one year (CAESAR), or a minimum of $0.5 \mathrm{~cm}$ between two 6-month assessments (PIVOTAL); or c) the aneurysm became symptomatic. Adherence to assigned treatment was very high across the four trials (UKSAT had the lowest adherence rate at $92.6 \%$ ) and at the end of the trials mortality status was ascertained in 100\% (ADAM; PIVOTAL; UKSAT) and 98\% (CAESAR) of participants. Approximately $62 \%, 48 \%, 31 \%$, and $75 \%$ of the patients in the selective surveillance group of the ADAM, CAESAR, PIVOTAL, and UKSAT studies, respectively, eventually underwent aneurysm repair.

See also Figure 1 and Figure 2 for the 'Risk of bias' summary. 


\begin{abstract}
Allocation
The methods of randomisation of the included studies ensured good balance across study groups. Adherence to assigned treatment was high, with the lowest adherence rate across the four trials at $92.6 \%$. Risk of allocation bias was very low.
\end{abstract}

\title{
Blinding
}

The nature of the interventions did not permit participants or observers to be blinded.

\section{Incomplete outcome data}

Mortality status was ascertained in 100\% (ADAM; PIVOTAL;UKSAT) and 98\%

(CAESAR) of participants. Moreover, the included studies experienced low loss to followup rates. Risk of attrition bias was very low.

\section{Selective reporting}

All included studies published findings on the main study outcome of this review. Risk of selective reporting bias was very low.

\section{Other potential sources of bias}

The CAESAR trial was originally funded by Cook Medical. During the enrolment phase of the trial, in December 2006, the sponsorship withdrew. However, the trial continued as full spontaneous research. According to the CAESAR study team the design, data collection, data analysis, data interpretation, and the writing of reports regarding the trial were at all times conducted independently from the sponsor. In summary, we could not exclude a possible conflict of interests in the CAESAR trial given that Cook Medical, the sponsor of the study, withdrew. The PIVOTAL trial was sponsored by Medtronic Vascular, who hold the database. Conflicts of interest were declared for two members of the PIVOTAL research team, who received funding from Medtronic and were consultants; a third member of the PIVOTAL research team had previously been a consultant for Medtronic. The Vascular Surgery Academic Coordinating Center of the Cleveland Clinic was independently responsible for the conduct of the study and its analysis. Other potential sources of bias for the remaining trials included in this review were not identified and are therefore unclear.

\section{Effects of interventions}

In both the UKSAT (UKSAT) and ADAM (ADAM) studies, the 30-day operative mortality in the immediate surgery group (5.5\% UKSAT and $2.1 \%$ ADAM) led to an early disadvantage in terms of survival in this study group. The lower 30-day operative mortality rate observed in the ADAM trial was expected due to the more restrictive study inclusion and exclusion criteria of the trial and better lung and renal function of the participants. In the CAESAR and PIVOTAL trials, the 30-day operative mortality in the immediate surgery group (0.6\% CAESAR and $0.3 \%$ PIVOTAL) led to an early disadvantage in terms of survival in this study group. The lower 30-day mortality rate observed in the CAESAR and PIVOTAL studies was expected due to the use of endovascular repair. 
In the UKSAT study, the long-term mortality rate (range 8 to 12 years, mean 10 years) was $63.9 \%$ in the immediate surgery group and $67.3 \%$ in the surveillance group. The UKSAT investigators found no statistically significant difference in long-term survival between the immediate surgery and surveillance groups (adjusted hazard ratio (HR) $0.88,95 \%$ CI 0.75 to 1.02). However, the hazards were non-proportional among study groups, as revealed by the survival curves crossing at approximately the three-year mark: the risk associated with operative mortality in the immediate repair group had resulted in an initial survival disadvantage for this study group compared to the selective surveillance group. The estimated adjusted HRs were in the direction of greater benefit of early surgery for younger patients and those with larger aneurysms but none of the tests for interaction were statistically significant. In contrast, recent analysis has suggested that the least fit patients benefited most from a policy of early surgery, although again the test of interaction was not significant (Brown 2008).

At the end of the study follow up (range 3.5 to 8.0 years, mean 4.9 years) the observed mortalities for the ADAM trial in the immediate repair and the selective surveillance groups were $25.1 \%$ and $21.5 \%$, respectively. However, in the UKSAT study the long-term survival was not statistically significantly different between study groups (adjusted HR 1.21, 95\% CI 0.95 to 1.54). The authors did not report violation of the proportional hazard assumption.

Study results showed a possible modification of effect with age and AAA size but, as in the UKSAT study, none of the tests for interaction were significant.

At the end of the study follow up (54 months, median 32.4 months) the estimated all-cause mortalities for the CAESAR trial in the immediate surgery group and the selective surveillance groups were $14.5 \%$ and $10.1 \%$ respectively. However, in the CAESAR study the long-term survival was not statistically different between study groups (HR $0.76,95 \%$ CI 0.30 to $1.93, \mathrm{P}=0.6$ ). The authors did not report a violation of the proportional hazard assumption.

At the end of the study follow up (range 0 to 41 months, mean $20 \pm 12$ months) the estimated all-cause mortalities for the PIVOTAL trial in the immediate surgery group and the selective surveillance groups were both $4.1 \%$. However, in the PIVOTAL study the long-term survival did not significantly differ between groups (HR 1.01, 95\% CI 0.49 to $2.07, \mathrm{P}=0.98$ ). The authors reported no evidence of non-proportional hazards between the two groups over time.

Meta-analyses of mortality were performed at one year for all four trials and at six years for the ADAM and UKSAT trials (the tabular data for analysis at this time point were available only for these studies). The meta analyses of mortality at one year to assess the effect of endovascular aneurysm repair (EVAR) (CAESAR and PIVOTAL only) and open surgery (UKSAT and ADAM only) and both EVAR and open surgery (CAESAR; PIVOTAL; UKSAT; ADAM) revealed a non-significant greater risk of mortality (Peto odds ratio (OR) $1.15,95 \%$ CI 0.59 to $2.25, \mathrm{I}^{2}=0 \%$ ) with early EVAR (Figure 3 ) and significantly higher risk of mortality with early open surgery (Peto OR $1.60,95 \%$ CI 1.10 to $2.32, \mathrm{I}^{2}=0 \%$ ) (Figure 4) or early repair by either method (Peto OR 1.48, 95\% CI 1.07 to $2.05, \mathrm{I}^{2}=0 \%$ ) (Figure 5). The meta analysis of mortality at six years (UKSAT and ADAM only) revealed a 
non-significantly higher risk of mortality associated with early open surgery (Peto OR at six years $1.11,95 \%$ CI 0.91 to $1.34, \mathrm{I}^{2}=0 \%$ ) (Figure 6).

In the UKSAT trial (UKSAT), the mean health service costs per patient were higher in the surgery than the surveillance group ( $£ 4978$ versus $£ 3194$; difference $£ 1064,95 \%$ CI 796 to 1332). This estimate accounted for surveillance visits, aneurysm repair, and any associated follow up. For example, if surveillance was conducted only once per annum, the mean cost difference in favour of surveillance widened to $£ 1256$ (95\% CI 990 to 1522). A $25 \%$ increase in cost of aneurysm repair further increased the difference, to $£ 1636$ (95\% CI 1340 to 1932). While neither the CAESAR nor PIVOTAL trials reported a cost comparison, the fact that the cost of endovascular repair is generally greater than that of the open repair used in the UKSAT means the cost difference would likely be even greater.

In the UKSAT trial, quality of life at randomisation was similar in the two groups but early surgery patients reported minor improvements in current health perceptions and less negative changes in bodily pain. In the CAESAR trial, comparable quality of life (SF-36) scores were seen in the immediate endovascular repair and surveillance groups at randomisation. At six months the total SF-36 and the Physical and Mental domain scores were all significantly higher with respect to baseline in the immediate repair group, while patients in the surveillance group scored lower. However, differences between the two groups diminished over time so that at the last assessment (one year or more after randomisation) there was no significant difference between immediate repair and surveillance $(\mathrm{P}=0.25)$.

\section{DISCUSSION}

The results from the four trials to date suggest no overall advantage to early surgery for small AAA. They do not allow additional guidelines for 'best-care' management of subgroups of patients since the trials did not provide data allowing analysis of results in these subgroups in relation to the intervention versus control and specified end-points. Furthermore, the more recent trials focused on the efficacy of EVAR and still failed to show benefit. Thus, both open and endovascular repair of small AAAs is not supported by currently available evidence. While the development of EVAR technology offers a significantly reduced operative mortality compared to open surgery and better short-term survival in general (Lederle 2009; Prinssen 2004; United Kingdom EVAR Trial Investigators 2010), reflected in the differences observed between Figure 3 and Figure 4, its efficacy is limited by high rates of re-operation for complications unique to EVAR. These include stent migration, stent wire fracture, metal fatigue, graft insertion site problems, and endoleak (Wilt 2006) over longer follow up (Becquemin 2011; De Bruin 2010; EVAR trial participants 2005). For small AAA, in particular, early EVAR does not appear to be superior to surveillance (see Figure 3, which shows a non-significant benefit in favour of surveillance) and its use could expose patients to unnecessary risk and ultimately higher healthcare costs (Ballard 2012). Likewise, as seen in Figure 4 and Figure 6, open repair offers no superior outcomes compared to surveillance for patients with small AAAs. 
Establishing optimal treatment guidelines for patient with small AAAs becomes even more relevant to improving public health and patient outcomes when the likelihood of increased AAA screening in the future is taken into account. The evidence from three randomised population screening trials, summarised in a Cochrane review, shows the benefits of screening older men for AAA (Cosford 2007). A national screening programme for all men aged 65 years and older has started in the UK (UK Screeening). The US Preventive Services Task Force (USPSTF) recommend AAA screening for men aged 65 to 75 years who have ever smoked (U.S. Preventive Task). More recently the Society for Vascular Surgery recommended screening of all men aged 60 to 85 years for AAA; women aged 60 to 85 years with cardiovascular risk factors; and men and women aged 50 years and older with a family history of AAA (Kent 2004). These recommendations are based on evidence that screening for AAA and repair of large AAAs (5.5 cm or more in diameter) leads to decreased AAA-specific mortality. However, the USPSTF also indicates that there is possible evidence of harms of screening and early treatment, including an increased number of surgeries with associated clinically-significant morbidity and mortality, and short-term psychological harms (U.S. Preventive Task). These harms are of most concern for patients with aneurysms in the 4.0 to $5.5 \mathrm{~cm}$ AAA size range, for whom current treatment guidelines are ambiguous.

\section{Summary of main results}

Findings from this review indicate that there was no survival advantage with immediate repair compared to selective surveillance in participants with asymptomatic aneurysms sized 4.0 to $5.5 \mathrm{~cm}$ in diameter. Results from the UKSAT, ADAM, CAESAR, and PIVOTAL trials showed no significant differences in survival between the study treatment groups for patients with AAA in particular size ranges or for patients in a particular age group. Uncertainty regarding the management of small AAAs is demonstrated by the current clinical guidelines, which do not provide any explicit therapeutic recommendation for AAAs in the range of 4.0 to $5.5 \mathrm{~cm}$ (Hirsch 2006; Wilt 2006). The management of small AAAs remains a grey area in clinical practice. Data regarding key factors for the management of AAA (such as AAA size; patient age, gender, and fitness) are much needed for the development of more definite and precise guidelines. In particular, examining the survival effect of immediate surgery versus selective surveillance for specific AAA size, AAA shape, and AAA location could reduce the uncertainty regarding the management of small AAA.

In summary, findings from the four trials to date suggest no advantage to early surgery for small AAA. Furthermore, the more recent trials focused on the efficacy of EVAR and still failed to show benefit. Thus, both open and endovascular repair of small AAAs is not supported by currently available evidence. The Society for Vascular Surgery guidelines strongly recommend surveillance for patients with a fusiform AAA of 4.0 to $5.4 \mathrm{~cm}$ (Chaikof 2009).

\section{Overall completeness and applicability of evidence}

This review is based on all trials to date which were suitable for inclusion. However, one limitation of the present review is the low proportion of women and non-Caucasian races in the trials. However, gender imbalance is exacerbated by the late onset of the disease in 
women and by the higher prevalence of AAA (approximately three times higher) in men than in women (Lederle 1997; Lederle 2000); and black race has been identified as having a strong negative association with AAA (ADAM). Thus, while it is indisputable that study results might be difficult to generalise to women and non-Caucasian men, this review provides critical data that can benefit the population with the highest prevalence of AAA and, therefore, the vast majority of patients with AAA. Future research regarding the management of small AAA should focus on minorities and women as data regarding these populations are lacking. In particular, future research should assess whether the AAA management recommendations, which are based on studies in which women are underrepresented, are applicable to women given their smaller body frames and, therefore, smaller abdominal aortas. This is critical given the higher risk of rupture experienced by women, the risk of rupture of small AAAs is four times higher in women than in men (Brown 2003).

\section{Quality of the evidence}

The UKSAT, ADAM, CAESAR, and PIVOTAL trials were very similar in design and, more importantly, were all well-conducted studies. All relevant studies were identified and included in this review. Moreover, all relevant data were obtained. In summary, besides the possible bias deriving from the conflict of interest regarding the CAESAR trial, the quality of evidence summarized in this review is sound.

\section{Potential biases in the review process}

Two authors (GF, MAMM) independently abstracted the data, which were cross-checked by the other authors (DJB, JTP). To further reduce bias, the role of JTP (trialist in the UKSAT study and author in the present review) in abstracting the data was limited to cross-checking the information abstracted by GF and MAMM. Strengths of the present review regarding potential biases are: 1) all relevant studies were identified and included in the review; 2) all the studies included in the review had very similar designs and methods; 3 ) relevant data for all studies were obtained; and 4) all the studies included in the review shared the same main outcome, and this outcome is the outcome of interest for this review too. As reported, however, we can not exclude possible bias deriving from the conflict of interest regarding the CAESAR and PIVOTAL trials.

\section{Agreements and disagreements with other studies or reviews}

To our knowledge, to date this is the only systematic review published on this topic.

\section{AUTHORS' CONCLUSIONS}

\section{Implications for practice}

Currently the evidence supports delaying the timing of AAA repair until the aneurysm reaches $5.5 \mathrm{~cm}$ in diameter. Findings from the four trials to date suggest no advantage to early repair of small AAAs, irrespective of whether open or endovascular repair is used. 


\section{Implications for research}

Data regarding key factors for the management of small AAA (such as AAA size; patient age, gender, and fitness) are much needed for the development of more definite and precise guidelines. In particular, examining the survival effect of immediate surgery versus selective surveillance for specific AAA size, AAA shape, and AAA location could reduce the uncertainty regarding the management of small AAA. Future research regarding the management of small AAAs should also focus on minorities and women as data regarding these populations are lacking. In particular, future research should assess whether the AAA management recommendations, which are based on studies in which women are underrepresented, are applicable to women given their smaller body frames and, therefore, smaller abdominal aortas.

\section{Acknowledgments}

The authors thank Briget da Graca for background research, writing, and in preparing this manuscript. The authors also thank Gerry Fowkes for his contribution to previous versions of this review.

\section{SOURCES OF SUPPORT}

Internal sources

- $\quad$ No sources of support supplied

External sources

- The Chief Scientist Office, Scottish Government Health Directorates, the Scottish Government, UK. The PVD Group editorial base is supported by the Chief Scientist Office

- $\quad$ National Institute for Health Research (NIHR), UK.

The PVD Group editorial base is supported by a programme grant from the NIHR.

- UKSAT: The Medical Research Council and the British Heart Foundation supported this trial, UK.

- $\quad$ ADAM: Supported by the Cooperative Studies Program of the Department of Veterans Affairs Office of Research and Development, Washington, DC, USA.

\section{CHARACTERISTICS OF STUDIES}

\section{Characteristics of included studies [ordered by study ID]}

ADAM

\begin{tabular}{ll}
\hline Methods & Study design: Intention to treat. \\
& Method of randomisation: Equal probability of assignment to each of the two study groups using \\
& automated telephone/computer. \\
& Concealment of allocation: Unblinded. \\
\hline Participants & Country: United States. \\
& Number: 1136. \\
& Age: $50-79$ years. \\
& Sex: Men $(\mathrm{n}=1126)$ and women $(\mathrm{n}=10)$. \\
& Inclusion criteria: Small $(4.0-5.5 \mathrm{~cm})$ non-tender asymptomatic AAAs considered fit for immediate \\
& surgery. Patients who were considered unfit for immediate surgery, had symptoms associated the \\
& aneurysm, were unable to attend the follow-up visit, or were unable to give informed consent were \\
& excluded. Patients who received a revascularisation procedure within three months of enrolment, \\
& who had a myocardial infarction within six months of enrolment, or who were expected to survive \\
& less than five years because of invasive cancer or other life-threatening disease were also excluded
\end{tabular}


Treatment: Surgery, $\mathrm{n}=569$ of whom 527 had immediate aneurysm repair: 42 had no elective operation due to death, refusal, etc.

Surveillance, $\mathrm{n}=567$ of whom 349 had aneurysm repair when met the criteria listed below (in $9 \%$, the procedures were performed despite an AAA that did not meet the repair criteria listed below). Patients assigned to the immediate surgery group received standard open repair within six weeks after randomisation while patients assigned to selective surveillance were followed without repair at similar regular intervals (at minimum once every six months) and surgery was performed within six weeks if: a) the aneurysm reached $5.5 \mathrm{~cm}$; or b) the aneurysm enlarged by a minimum of $0.7 \mathrm{~cm}$ in six months or $1.0 \mathrm{~cm}$ in 1 year; or c) the aneurysm became symptomatic

\begin{tabular}{|c|c|c|}
\hline Outcomes & \multicolumn{2}{|c|}{$\begin{array}{l}\text { Primary: Survival during mean follow up (range } 3.5 \text { to } 8.0 \text { years, mean } 4.9 \text { years) ( } 30 \text {-day surgical } \\
\text { mortality) } \\
\text { Secondary: Healthcare costs }\end{array}$} \\
\hline \multicolumn{3}{|l|}{ Notes } \\
\hline \multicolumn{3}{|l|}{ Risk of bias } \\
\hline Bias & Authors' judgement & Support for judgement \\
\hline $\begin{array}{l}\text { Random } \\
\text { sequence } \\
\text { generation } \\
\text { (selection bias) }\end{array}$ & Low risk & $\begin{array}{l}\text { Themethod of randomisation was of equal probability } \\
\text { of assignment to each of the two study groups using } \\
\text { automated telephone/computer }\end{array}$ \\
\hline $\begin{array}{l}\text { Allocation } \\
\text { concealment } \\
\text { (selection bias) }\end{array}$ & Unclear risk & Concealment of allocation: Unblinded \\
\hline $\begin{array}{l}\text { Blinding of } \\
\text { participants and } \\
\text { personnel } \\
\text { (performance } \\
\text { bias) } \\
\text { All outcomes }\end{array}$ & Unclear risk & Cannot blind participants \\
\hline $\begin{array}{l}\text { Blinding of } \\
\text { outcome } \\
\text { assessment } \\
\text { (detection bias) } \\
\text { All outcomes }\end{array}$ & Low risk & $\begin{array}{l}\text { Unlikely given the study outcome (mortality) and low } \\
\text { lost of follow-up rate. Vital status was assessed using } \\
\text { the same methodology for both patients in the } \\
\text { immediate repair group and patients in the routine } \\
\text { ultrasound surveillance group -in case } \\
\text { misclassification occurred this would have been non- } \\
\text { differential and its impact on the study results would } \\
\text { be limited }\end{array}$ \\
\hline $\begin{array}{l}\text { Incomplete } \\
\text { outcome data } \\
\text { (attrition bias) } \\
\text { All outcomes }\end{array}$ & Low risk & $\begin{array}{l}\text { Unlikely given the study outcome (mortality) and low } \\
\text { lost of follow-up rate }\end{array}$ \\
\hline $\begin{array}{l}\text { Selective } \\
\text { reporting } \\
\text { (reporting bias) }\end{array}$ & Low risk & $\begin{array}{l}\text { Authors published findings on all the study outcomes } \\
\text { including the study outcome of this review }\end{array}$ \\
\hline Other bias & Low risk & We did not identify other possible risk of bias \\
\hline
\end{tabular}

CAESAR

\begin{tabular}{ll}
\hline Methods & Study design: Intention to treat. \\
& Method of randomisation: Randomisation was designed with equal probability $(1: 1$ ratio) of \\
& assignment to either early EVAR or surveillance by means of a computed generated random \\
& number list, stratified by centre using a permuted block design and carried out online through the \\
& internet. \\
& Concealment of allocation: Unblinded. \\
\hline Participants & Country: Italy. \\
& Number: 360. \\
& Sex: Men $(\mathrm{n}=345)$ and women $(\mathrm{n}=15)$. \\
& Age: $50-79$ years. \\
& Inclusion criteria: Patients with small $(4.1-5.4 \mathrm{~cm})$ asymptomatic AAAs, without high surgical \\
& risk, and who would have benefited from early repair. Patients were excluded if they had severe
\end{tabular}

Cochrane Database Syst Rev. Author manuscript; available in PMC 2014 September 25. 
co-morbidities or a suprarenal/thoracic aorta $\geq 4.0 \mathrm{~cm}$, needed urgent repair, or were unable or unwilling to give informed consent or follow the protocol

\begin{tabular}{|c|c|c|}
\hline Interventions & \multicolumn{2}{|c|}{$\begin{array}{l}\text { Treatment: Surgery, } \mathrm{n}=182 \text { of whom } 175 \text { had immediate EVAR surgery: } 6 \text { declined treatment } \\
\text { and } 1 \text { underwent open repair according to patient's choice } \\
\text { Surveillance, } \mathrm{n}=178 \text { of whom } 172 \text { had aneurysm repair when met the criteria below ( } 6 \text { patients } \\
\text { had EVAR against protocol: } 5 \text { per patient choice and } 1 \text { with a surgeon not participating in the } \\
\text { study) } \\
\text { Patients assigned to early EVAR underwent aneurysm repair a median of } 22 \text { days after } \\
\text { randomisation while patients assigned to surveillance were seen every } 6 \text { months and repair } \\
\text { allowed if the aneurysm grew to } 5.5 \mathrm{~cm} \text { diameter in size, rapidly increased in diameter }(>1 \mathrm{~cm} / \\
\text { year) or became symptomatic }\end{array}$} \\
\hline Outcomes & \multicolumn{2}{|c|}{$\begin{array}{l}\text { Primary: Mortality from any cause } \\
\text { Secondary: 1) aneurysm-related deaths (defined as and death caused directly or indirectly by } \\
\text { aneurysm rupture or aneurysm repair), 2) aneurysm rupture, 3) perioperative ( } 30 \text { days or inpatient) } \\
\text { or late adverse events (defined according to SVS/AAVS reporting standards), 4) conversion to } \\
\text { open repair, 5) loss of treatment options (anatomical suitability for EVAR) and 6) aneurysm } \\
\text { growth rate }\end{array}$} \\
\hline \multicolumn{3}{|l|}{ Notes } \\
\hline \multicolumn{3}{|l|}{ Risk of bias } \\
\hline Bias & Authors' judgement & Support for judgement \\
\hline $\begin{array}{l}\text { Random } \\
\text { sequence } \\
\text { generation } \\
\text { (selection bias) }\end{array}$ & Low risk & $\begin{array}{l}\text { Randomisation was designed with equal probability ( } 1: 1 \text { ratio) of } \\
\text { assignment to either early EVAR or surveillance by means of a } \\
\text { computed-generated random number list, stratified by centre using a } \\
\text { permuted block design and carried out online through the internet. }\end{array}$ \\
\hline $\begin{array}{l}\text { Allocation } \\
\text { concealment } \\
\text { (selection bias) }\end{array}$ & Unclear risk & Concealment of allocation: Unblinded \\
\hline $\begin{array}{l}\text { Blinding of } \\
\text { participants and } \\
\text { personnel } \\
\text { (performance } \\
\text { bias) } \\
\text { All outcomes }\end{array}$ & Unclear risk & Cannot blind participants \\
\hline $\begin{array}{l}\text { Blinding of } \\
\text { outcome } \\
\text { assessment } \\
\text { (detection bias) } \\
\text { All outcomes }\end{array}$ & Low risk & $\begin{array}{l}\text { Unlikely given the study outcome (mortality) and low lost of follow- } \\
\text { up rate. Vital status was assessed using the same methodology for } \\
\text { both patients in the immediate repair group and patients in the routine } \\
\text { ultrasound surveillance group -in case misclassification occurred } \\
\text { thiswould have been non-differential and its impact on the study } \\
\text { results would be limited }\end{array}$ \\
\hline $\begin{array}{l}\text { Incomplete } \\
\text { outcome data } \\
\text { (attrition bias) } \\
\text { All outcomes }\end{array}$ & Low risk & $\begin{array}{l}\text { Unlikely given the study outcome (mortality) and low lost of follow- } \\
\text { up rate }\end{array}$ \\
\hline $\begin{array}{l}\text { Selective } \\
\text { reporting } \\
\text { (reporting bias) }\end{array}$ & Low risk & Authors published findings on the main study outcome of this review \\
\hline Other bias & High risk & $\begin{array}{l}\text { Conflict of interests: Cook Medical, the sponsor of the study, } \\
\text { withdrew }\end{array}$ \\
\hline
\end{tabular}

\section{PIVOTAL}

\begin{tabular}{ll}
\hline Methods & Study design: Intention to treat. \\
& Method of randomisation: The randomisation procedure was created with equal probability of \\
& assignment to each of the treatment groups by means of a computer-generated random-number code \\
& Concealment of allocation: Unblinded. \\
\hline Participants & Country: United States. \\
& Number: 728. \\
& Sex: Men $(\mathrm{n}=631)$ and women $(\mathrm{n}=97)$. \\
& Age: $40-90$ years.
\end{tabular}

Cochrane Database Syst Rev. Author manuscript; available in PMC 2014 September 25. 
Inclusion criteria: Patients with small $(4.0-5.0 \mathrm{~cm})$ AAAs. Patients were excluded from the study if they had evidence of symptoms referable to the aneurysm, an abdominal or thoracic repair, an aneurysm originating $\leq 1.0 \mathrm{~cm}$ from the most distal main renal artery, life expectancy of $<3$ years, inability to provide informed consent, predicted noncompliance with the protocol, Society of

Vascular Surgery (SVS) score > 2 with the exception of age and controlled hypertension, baseline serum creatinine level $>2.5 \mathrm{mg} / \mathrm{dL}$, or when the patient did not meet the indications for use of the endograft device

Interventions Treatment: Surgery, $\mathrm{n}=366$ of whom 322 had immediate EVAR surgery: 4 underwent open surgery, 6 underwent repair outside of the 30-day window of randomisation, 9 were withdrawn per patient request, 10 were withdrawn per physician request for deteriorating health status between randomisation and scheduled repair, 2 were treated with an endograft device that was not in the protocol, and 13 received no repair for reasons not specified

Surveillance, $n=362$ of whom 100 had aneurysm repair when met the criteria listed below Patients assigned to early EVAR underwent aneurysm repair $\leq 30$ days of randomisation while patients assigned to surveillance were seen at 1 month, 6 months, and every 6 months thereafter for a minimum of 36 months and a maximum of 60 months after operation. Patients were offered aneurysm repair when symptoms thought referable to the aneurysm developed, when the diameter of the aneurysm reached $5.5 \mathrm{~cm}$, or when the aneurysm enlarged $\searrow 0.5 \mathrm{~cm}$ between any two 6-month assessments

\begin{tabular}{|c|c|c|}
\hline Outcomes & \multicolumn{2}{|c|}{$\begin{array}{l}\text { Primary: To determine whether early endovascular repair of aneurysms } 4.0-5.0 \mathrm{~cm} \text { in diameter is } \\
\text { superior to surveillance with respect to the frequency of rupture or aneurysmrelated death } \\
\text { Secondary: N/A }\end{array}$} \\
\hline \multicolumn{3}{|l|}{ Notes } \\
\hline \multicolumn{3}{|l|}{ Risk of bias } \\
\hline Bias & Authors' judgement & Support for judgement \\
\hline $\begin{array}{l}\text { Random } \\
\text { sequence } \\
\text { generation } \\
\text { (selection bias) }\end{array}$ & Low risk & $\begin{array}{l}\text { The randomisation procedure was designed to provide } \\
\text { equal probability of assignment to each of the } \\
\text { treatment groups by means of a computer-generated } \\
\text { random-number code }\end{array}$ \\
\hline $\begin{array}{l}\text { Allocation } \\
\text { concealment } \\
\text { (selection bias) }\end{array}$ & Unclear risk & Concealment of allocation: Unblinded \\
\hline $\begin{array}{l}\text { Blinding of } \\
\text { participants and } \\
\text { personnel } \\
\text { (performance } \\
\text { bias) } \\
\text { All outcomes }\end{array}$ & Unclear risk & Cannot blind participants \\
\hline $\begin{array}{l}\text { Blinding of } \\
\text { outcome } \\
\text { assessment } \\
\text { (detection bias) } \\
\text { All outcomes }\end{array}$ & Low risk & $\begin{array}{l}\text { Unlikely given the study outcome (mortality) and low } \\
\text { lost of follow-up rate. Vital status was assessed using } \\
\text { the same methodology for both patients in the } \\
\text { immediate repair group and patients in the routine } \\
\text { ultrasound surveillance group - in case } \\
\text { misclassification occurred this would have been non- } \\
\text { differential and its impact on the study results would } \\
\text { be limited }\end{array}$ \\
\hline $\begin{array}{l}\text { Incomplete } \\
\text { outcome data } \\
\text { (attrition bias) } \\
\text { All outcomes }\end{array}$ & Low risk & $\begin{array}{l}\text { Unlikely given the study outcome (mortality) and low } \\
\text { lost of follow-up rate }\end{array}$ \\
\hline $\begin{array}{l}\text { Selective } \\
\text { reporting } \\
\text { (reporting bias) }\end{array}$ & Low risk & $\begin{array}{l}\text { Authors published findings on the main study outcome } \\
\text { of this review }\end{array}$ \\
\hline Other bias & High risk & $\begin{array}{l}\text { Conflicts of interest: The study was funded by } \\
\text { Medtronic Vascular, which now holds the trial } \\
\text { database. The funding source was not specified in the } \\
\text { report of trial results, butwas specified in the } 2009 \\
\text { paper describing the rationale and protocol for the } \\
\text { study (PIVOTAL). In addition, two members of the } \\
\text { research team were acknowledged as paid consultants } \\
\text { of Medtronic }\end{array}$ \\
\hline
\end{tabular}

\section{UKSAT}




\begin{tabular}{|c|c|c|}
\hline Methods & \multicolumn{2}{|c|}{$\begin{array}{l}\text { Study design: Intention to treat. } \\
\text { Method of randomisation: Concealed randomisation using automated telephone/computer. } \\
\text { Concealment of allocation: Unblinded. }\end{array}$} \\
\hline Participants & \multicolumn{2}{|c|}{$\begin{array}{l}\text { Country: United Kingdom. } \\
\text { Number: } 1090 . \\
\text { Sex: Men }(\mathrm{n}=902) \text { and women }(\mathrm{n}=188) . \\
\text { Age: } 60-76 \text { years. } \\
\text { Inclusion criteria: Symptomless (non-tender) infrarenal aneurysm. Maximum A-P diameter } 4.0 \text { - } \\
5.5 \mathrm{~cm} \text {. Fit for elective surgery }\end{array}$} \\
\hline Interventions & \multicolumn{2}{|c|}{$\begin{array}{l}\text { Treatment: Surgery, } \mathrm{n}=563 \text { of whom } 528 \text { had immediate aneurysm repair; } 35 \text { had no elective } \\
\text { operation due to death, refusal, etc. } \\
\text { Control: Surveillance, } \mathrm{n}=527 \text { of whom } 401 \text { had aneurysm repair when met the criteria listed } \\
\text { below. } \\
\text { Patients assigned to the immediate surgery group received standard open repair within six weeks } \\
\text { after randomisation while patients assigned to selective surveillance were followed without repair } \\
\text { at similar regular intervals (at minimum once every six months) and surgery was performed within } \\
\text { six weeks if: a) the aneurysm reached } 5.5 \mathrm{~cm} \text {; or b) the aneurysm enlarged by a minimum } 1.0 \mathrm{~cm} \\
\text { in } 1 \text { year; or c) the aneurysm became tender or symptomatic }\end{array}$} \\
\hline Outcomes & \multicolumn{2}{|c|}{$\begin{array}{l}\text { Primary: Survival during mean follow up (range } 8 \text { to } 12 \text { years, mean } 10 \text { years) (30-day surgical } \\
\text { mortality) } \\
\text { Secondary: Healthcare costs }\end{array}$} \\
\hline \multicolumn{3}{|l|}{ Notes } \\
\hline \multicolumn{3}{|l|}{ Risk of bias } \\
\hline Bias & Authors' judgement & Support for judgement \\
\hline $\begin{array}{l}\text { Random } \\
\text { sequence } \\
\text { generation } \\
\text { (selection bias) }\end{array}$ & Low risk & $\begin{array}{l}\text { Concealed randomisation using automated telephone/ } \\
\text { computer }\end{array}$ \\
\hline $\begin{array}{l}\text { Allocation } \\
\text { concealment } \\
\text { (selection bias) }\end{array}$ & Unclear risk & Concealment of allocation: Unblinded \\
\hline $\begin{array}{l}\text { Blinding of } \\
\text { participants and } \\
\text { personnel } \\
\text { (performance } \\
\text { bias) } \\
\text { All outcomes }\end{array}$ & Unclear risk & Cannot blind participants \\
\hline $\begin{array}{l}\text { Blinding of } \\
\text { outcome } \\
\text { assessment } \\
\text { (detection bias) } \\
\text { All outcomes }\end{array}$ & Low risk & $\begin{array}{l}\text { Unlikely given the study outcome (mortality) and low } \\
\text { lost of follow-up rate. Vital status was assessed using } \\
\text { the same methodology for both patients in the } \\
\text { immediate repair group and patients in the routine } \\
\text { ultrasound surveillance group -in case } \\
\text { misclassification occurred this would have been non- } \\
\text { differential and its impact on the study results would } \\
\text { be limited }\end{array}$ \\
\hline $\begin{array}{l}\text { Incomplete } \\
\text { outcome data } \\
\text { (attrition bias) } \\
\text { All outcomes }\end{array}$ & Low risk & $\begin{array}{l}\text { Unlikely given the study outcome (mortality) and low } \\
\text { lost of follow-up rate }\end{array}$ \\
\hline $\begin{array}{l}\text { Selective } \\
\text { reporting } \\
\text { (reporting bias) }\end{array}$ & Low risk & $\begin{array}{l}\text { Authors published findings on all the study outcomes } \\
\text { including the study outcome of this review }\end{array}$ \\
\hline Other bias & Low risk & We did not identify other possible risk of bias \\
\hline
\end{tabular}




\section{Characteristics of excluded studies [ordered by study ID]}

\begin{tabular}{ll}
\hline Study & Reason for exclusion \\
\hline Canadian Trial & $\begin{array}{l}\text { This trial was begun but stopped because of an inadequate rate of recruitment after } \mathrm{n}=104 \text { had been } \\
\text { enrolled (Cole CW, personal communication, 1998) }\end{array}$ \\
\hline
\end{tabular}

\section{DATA AND ANALYSES}

\section{Comparison 1}

Immediate repair (EVAR) versus ultrasound

surveillance at one year

\begin{tabular}{lcccc}
\hline $\begin{array}{l}\text { Outcome or } \\
\text { subgroup title }\end{array}$ & No. of studies & No. of participants & Statistical method & Effect size \\
\hline 1 Mortality & 2 & 831 & Peto Odds Ratio (Peto, Fixed, 95\% & $1.15[0.59,2.25]$ \\
\hline
\end{tabular}

\section{Comparison 2}

Immediate repair (open surgery) versus ultrasound surveillance at one year

\begin{tabular}{lcccc}
\hline $\begin{array}{l}\text { Outcome or } \\
\text { subgroup title }\end{array}$ & No. of studies & No. of participants & Statistical method & Effect size \\
\hline 1 Mortality & 2 & 2226 & Peto Odds Ratio (Peto, Fixed, 95\% & $1.60[1.10,2.32]$ \\
\hline
\end{tabular}

\section{Comparison 3}

Immediate repair (either EVAR or OPEN) versus ultrasound surveillance at one year

\begin{tabular}{lcccc}
\hline $\begin{array}{l}\text { Outcome or } \\
\text { subgroup title }\end{array}$ & No. of studies & No. of participants & Statistical method & Effect size \\
\hline 1 Mortality & 4 & 3057 & Peto Odds Ratio (Peto, Fixed, 95\% & $1.48[1.07,2.05]$ \\
\hline
\end{tabular}

\section{Comparison 4}

Immediate repair (open surgery) versus ultrasound surveillance at six years

\begin{tabular}{lcccc}
\hline $\begin{array}{l}\text { Outcome or } \\
\text { subgroup title }\end{array}$ & No. of studies & No. of participants & Statistical method & Effect size \\
\hline 1 Mortality & 2 & 2226 & Peto Odds Ratio (Peto, Fixed, 95\% & $1.11[0.91,1.34]$ \\
\hline
\end{tabular}


Comparison 5

Costs of immediate repair versus ultrasound surveillance

\begin{tabular}{|c|c|c|c|c|}
\hline $\begin{array}{c}\text { Outcome or subgroup } \\
\text { title }\end{array}$ & No. of studies & No. of participants & Statistical method & Effect size \\
\hline $\begin{array}{l}1 \text { Health service costs } \\
\text { (GBP) }\end{array}$ & 1 & & $\begin{array}{c}\text { Mean Difference (IV, Fixed, } \\
\text { 95\% CI) }\end{array}$ & Totals not selected \\
\hline
\end{tabular}

\section{WHAT'S NEW}

Last assessed as up-to-date: 8 February 2012.

\begin{tabular}{lll}
\hline Date & Event & Description \\
\hline 17 October 2011 & New search has been performed & New author added \\
\hline 17 October 2011 & $\begin{array}{l}\text { New citation required but conclusions have not } \\
\text { changed }\end{array}$ & $\begin{array}{l}\text { CAESAR and PIVOTAL results included in } \\
\text { the analysis }\end{array}$ \\
\hline
\end{tabular}

\section{HISTORY}

Protocol first published: Issue 3, 1999

Review first published: Issue 4, 1999

\begin{tabular}{lll}
\hline Date & Event & Description \\
\hline 20 May 2008 & $\begin{array}{l}\text { New search has been } \\
\text { performed }\end{array}$ & $\begin{array}{l}\text { ADAM trial results incorporated in analysis. CAESAR and } \\
\text { PIVOTAL trials added to ongoing studies }\end{array}$ \\
\hline 8 April 2008 & Amended & Converted to new review format. \\
\hline
\end{tabular}

\section{References to studies included in this review}

ADAM \{published data only\} . Lederle FA, Johnson GR, Wilson SE, Acher CW, Ballard DJ, Littooy FN, et al. Quality of life, impotence, and activity level in a randomized trial of immediate repair versus surveillance of small abdominal aortic aneurysm. Journal of Vascular Surgery. 2003; 38(4):745-52. [PubMed: 14560224]

Lederle FA, Johnson GR, Wilson SE, Chute EP, Hye RJ, Makaroun MS, et al. The aneurysm detection and management study screening programme: validation cohort and final results. Aneurysm Detection and Management Veterans Affairs Cooperative Study Investigators. Archives of Internal Medicine. 2000; 160(10):1425-30. [PubMed: 10826454]

Lederle FA, Johnson GR, Wilson SE, Chute EP, Littooy FN, Bandyk D, et al. Prevalence and associations of abdominal aortic aneurysm detected through screening. Aneurysm Detection and Management (ADAM) Veterans Affairs Cooperative Study Group. Annals of Internal Medicine. 1997; 126(6):441-9. [PubMed: 9072929]

Lederle FA, Johnson GR, Wilson SE, Gordon IL, Chute EP, Littooy FN, et al. The Aneurysm Detection and Management (ADAM) Veterans Affairs Cooperative Study Investigators. 
Relationship of age, gender, race, and body size to infrarenal aortic diameter. Journal of Vascular Surgery. 1997; 26(4):595-601. [PubMed: 9357459]

Lederle FA, Wilson SE, Johnson GR, Littooy FN, Acher C, Messina LM, et al. Design of the abdominal aortic Aneurysm Detection and Management Study. Journal of Vascular Surgery. 1994; 20(2):296-303. [PubMed: 8040955]

Lederle FA, Wilson SE, Johnson GR, Reinke DB, Littooy FN, Acher CW, et al. Immediate repair compared with surveillance of small abdominal aortic aneurysms. New England Journal of Medicine. 2002; 346(19):1437-44. [PubMed: 12000813]

CAESAR \{published data only\} . Cao, P. [accessed 14 November 2011] Comparison of Surveillance Versus Aortic Endografting for Small Aneurysm Repair. http://clinicaltrials.gov/ct/ show/NCT00118573?order=1http://clinicaltrials.gov/ct/show/NCT00118573?order=1

Cao P, CAESAR Trial Collaborators. Comparison of surveillance vs Aortic Endografting for Small Aneurysm Repair (CAESAR) trial: study design and progress. European Journal of Vascular and Endovascular Surgery. 2005; 30(3):245-51. [PubMed: 16130206]

Cao P, De Rango P, Verzini F, Parlani G, Romano L, Cieri E, for the CAESAR Trial Group. Comparison of Surveillance Versus Aortic Endografting for Small Aneurysm Repair (CAESAR): Results from a randomised trial. European Journal of Vascular and Endovascular Surgery. 2011; 41(1):13-25. [PubMed: 20869890]

De Rango P, Verzini F, Parlani G, Cieri E, Romano L, Loschi D, et al. Quality of life in patients with small abdominal aortic aneurysm: the effect of early endovascular repair versus surveillance in the CAESAR trial. European Journal of Vascular and Endovascular Surgery. 2011; 41(3):324-31. [PubMed: 21145269]

PIVOTAL \{published data only\} . Ouriel, K. [accessed 14 November 2011] The (PIVOTAL) study. http://clinicaltrials.gov/ct/show/NCT00444821?order=1http://clinicaltrials.gov/ct/show/ NCT00444821?order=1

Ouriel K. The PIVOTAL study: A randomized comparison of endovascular repair versus surveillance in patients with smaller abdominal aortic aneurysms. Journal of Vascular Surgery. 2009; 49(1): 266-9. [PubMed: 19174266]

Ouriel K, Clair DG, Kent CK, Zarins CK, PIVOTAL investigators. Endovascular repair compared with surveillance for patients with small abdominal aortic aneurysms. Journal of Vascular Surgery. 2009; 50(2):449.

Ouriel K, Clair DG, Kent KC, Zarins CK, for the Positive Impact of Endovascular Options for treating Aneurysms Early (PIVOTAL) Investigators. Endovascular repair compared with surveillance for patients with small abdominal aortic aneurysms. Journal of Vascular Surgery. 2010; 51(5):1081-7. [PubMed: 20304589]

UKSAT \{published data only\} . Brown LC, Thompson SG, Greenhalgh RM, Powell JT, UK Small Aneurysm Trial Participants. Fit patients with small abdominal aortic aneurysms (AAAs) do not benefit from early intervention. Journal of Vascular Surgery. 2008; 48(6):1375-81. [PubMed: 19118733]

Powell JT, Brown LC, Forbes JF, Fowkes FG, Greenhalgh RM, Ruckley, et al. Final 12-year followup of surgery versus surveillance in the UK Small Aneurysm Trial. British Journal of Surgery. 2007; 94(6):702-8. [PubMed: 17514693]

The UK Small Aneurysm Trial Participants. Health service costs and quality of life for early elective surgery or ultrasonographic surveillance for small abdominal aortic aneurysms. Lancet. 1998; 352(9141):1656-60. [PubMed: 9853437]

The UK Small Aneurysm Trial Participants. Mortality results for randomised controlled trial of early elective surgery or ultrasonographic surveillance for small abdominal aortic aneurysms. Lancet. 1998; 352(9141):1649-55. [PubMed: 9853436]

The UK Small Aneurysm Trial Participants. The UK Small Aneurysm Trial: design, methods and progress. European Journal of Vascular and Endovascular Surgery. 1995; 9(1):42-8. [PubMed: 7664011]

The United Kingdom Small Aneurysm Trial Participants. Long-term outcomes of immediate repair compared with surveillance of small abdominal aortic aneurysms. New England Journal of Medicine. 2002; 346(19):1445-52. [PubMed: 12000814] 
UK Small Aneurysm Trial Participants. The long-term prognosis of patients with small abdominal aortic aneurysm following surgery or surveillance: 12-year final follow-up of patients enrolled in. The Vascular Society of Great Britain \& Ireland Yearbook 2006. 2006:78.

\section{References to studies excluded from this review}

Canadian Trial \{unpublished data only\} . Cole CW. Conversation with: Dr Ballard and Prof Powell. 1998 personal communication.

\section{Additional references}

Ballard 1992 . Ballard, DJ.; Etchason, JA.; Hilborne, LH.; Campion, ME.; Kamberg, CJ.; Solomon, DH., et al. Abdominal Aortic Aneurysm Surgery. A Literature Review and Ratings of Appropriateness and Necessity. RAND; Santa Monica(CA): 1992.

Ballard 2012 . Ballard DJ, Filardo G, da Graca B, Powell JT. Clinical practice change requires more than comparative effectiveness evidence: abdominal aortic aneurysm management in the USA. Journal of Comparative Effectiveness Research. 2012; 1(1):31-44. [PubMed: 24237296]

Becquemin 2011 . Becquemin JP, Pillet JC, Lescalie F, Sapoval M, Goueffic Y, Lermusiaux P, et al. A randomized controlled trial of endovascular aneurysm repair versus open surgery for abdominal aortic aneurysms in low-to moderate-risk patients. Journal of Vascular Surgery. 2011; 53(5):1167-73. [PubMed: 21276681]

Bernstein 1984 . Bernstein EF, Chan EL. Abdominal aortic aneurysm in high-risk patients. Outcome of selective management based on size and expansion rate. Annals of Surgery. 1984; 200(3):25563. [PubMed: 6465980]

Brown 2003 . Brown PM, Zelt DT, Sobolev B. The risk of rupture in untreated aneurysms: the impact of size, gender, and expansion rate. Journal of Vascular Surgery. 2003; 37(2):280-4. [PubMed: 12563196]

Brown 2008 . Brown, LC.; Thompson, SG.; Greenhalgh, RM.; Powell, JT. Do very fit patients with small abdominal aortic aneurysm benefit from early intervention?; Vascular Surgical Meeting; San Diego. 2008; Jun 4-8.

Chaikof 2009 . Chaikof EL, Brewster DC, Dalman RL, Makaroun MS, Illig KA, Sicard GA, et al. SVS practice guidelines for the care of patients with an abdominal aortic aneurysm: Executive summary. Journal of Vascular Surgery. 2009; 50(4):880-96. [PubMed: 19786241]

Cosford 2007 . Cosford PA, Leng GC, Thomas J. Screening for abdominal aortic aneurysm. Cochrane Database of Systematic Reviews. 2007; (2) DOI: 10.1002/14651858.CD002945.pub2.

De Bruin 2010 . De Bruin JL, Baas AF, Buth J, Prinssen M, Verhoeven EL, Cuypers PW, et al. Long-term outcome of open or endovascular repair of abdominal aortic aneurysm. New England Journal of Medicine. 2010; 362(20):1881-9. [PubMed: 20484396]

Ernst 1993 . Ernst CB. Abdominal aortic aneurysm. New England Journal of Medicine. 1993; 328(16):1167-72. [PubMed: 8455684]

EVAR trial participants 2005 . EVAR trial participants. Endovascular aneurysm repair versus open repair in patients with abdominal aortic aneurysm (EVAR trial 1): randomised controlled trial. Lancet. 2005; 365(9478):2179-86. [PubMed: 15978925]

Higgins 2011 . The Cochrane Collaboration. Higgins, JPT.; Green, S., editors. Cochrane Handbook for Systematic Reviews of Interventions Version 5.1.0 [updated March 2011]. 2011. Available from www.cochrane-handbook.org

Hirsch 2006 . Hirsch AT, Haskal ZJ, Hertzer NR, Bakal CW, Creager MA, Halperin JL, et al. ACC/AHA 2005 Practice Guidelines for the management of patients with peripheral arterial disease (lower extremity, renal, mesenteric, and abdominal aortic): a collaborative report from the American Association for Vascular Surgery/Society for Vascular Surgery, Society for Cardiovascular Angiography and Interventions, Society for Vascular Medicine and Biology, Society of Interventional Radiology, and the ACC/AHA Task Force on Practice Guidelines (Writing Committee to Develop Guidelines for the Management of Patients With Peripheral Arterial Disease): endorsed by the American Association of Cardiovascular and Pulmonary Rehabilitation; National Heart, Lung, and Blood Institute; Society for Vascular Nursing; 
TransAtlantic Inter-Society Consensus; and Vascular Disease Foundation. Circulation. 2006; 113(11):e463-e654. [PubMed: 16549646]

Kent 2004 . Kent KC, Zwolak RM, Jaff MR, Hollenbeck ST, Thompson RW, Schermerhorn ML, et al. Screening for abdominal aortic aneurysm: a consensus statement. Journal of Vascular Surgery. 2004; 39(1):267-9. [PubMed: 14718853]

Lederle 1996 . Lederle FA. Risk of rupture of large abdominal aortic aneurysms. Disagreement among vascular surgeons. Archives of Internal Medicine. 1996; 156(9):1007-9. [PubMed: 8624165]

Lederle 1997 . Lederle FA, Johnson GR, Wilson SE, Chute EP, Littooy FN, Bandyk D, et al. Prevalence and associations of abdominal aortic aneurysm detected through screening. Aneurysm Detection and Management (ADAM) Veterans Affairs Cooperative Study Group. Annals of Internal Medicine. 1997; 126(6):441-9. [PubMed: 9072929]

Lederle 2000 . Lederle FA, Johnson GR, Wilson SE, Chute EP, Hye RJ, Makaroun MS, et al. Aneurysm Detection and Management Veterans Affairs Cooperative Study Investigators. The aneurysm detection and management study screening program: validation cohort and final results. Archives of Internal Medicine. 2000; 160(10):1425-30. [PubMed: 10826454]

Lederle 2003 . Lederle FA, Nelson DB, Joseph AM. Smokers' relative risk for aortic aneurysm compared with other smoking-related diseases: a systematic review. Journal of Vascular Surgery. 2003; 38(2):329-34. [PubMed: 12891116]

Lederle 2009 . Lederle FA, Freischlag JA, Kyriakides TC, Padberg FT Jr, Matsumura JS, Kohler TR. Outcomes following endovascular vs open repair of abdominal aortic aneurysm: a randomized trial. JAMA. 2009; 302(14):1535-42. [PubMed: 19826022]

Nevitt 1989 . Nevitt MP, Ballard DJ, Hallett JW Jr. Prognosis of abdominal aortic aneurysms. A population-based study. New England Journal of Medicine. 1989; 321(15):1009-14. [PubMed: 2674715]

Prinssen 2004 . Prinssen M, Verhoeven EL, Buth J, Cuypers PW, van Sambeek MR, Balm R. A randomized trial comparing conventional and endovascular repair of abdominal aortic aneurysms. New England Journal of Medicine. 2004; 351(16):1607-18. [PubMed: 15483279]

Shah 1997 . Shah PK. Inflammation, metalloproteinases, and increased proteolysis: an emerging pathophysiological paradigm in aortic aneurysm. Circulation. 1997; 96:2115-7. [PubMed: 9337176]

Stonebridge 1996 . Stonebridge, PA.; Ruckley, CV. Abdominal aortic aneurysms. In: Tooke, JE; Lowe, GDO., editors. A Textbook of Vascular Medicine. Arnold; London: 1996. p. 176-90.

US Preventive Task . U.S. Preventive Services Task Force. [accessed 27 March 2008] Screening for abdominal aortic aneurysm. http://www.ahrq.gov/clinic/uspstf/uspsaneu.htmhttp:// www.ahrq.gov/clinic/uspstf/uspsaneu.htm

UK Screeening . [accessed March 30 2008] UK National Screening Committee statement on Prime Minister's Health speech. http://www.nsc.nhs.uk/pdfs/NSC-pressrelease-080108.pdfhttp:// www.nsc.nhs.uk/pdfs/NSC-pressrelease-080108.pdf

United Kingdom EVAR Trial Investigators 2010 . United Kingdom EVAR Trial Investigators. Greenhalgh RM, Brown LC, Powell JT, Thompson SG, Epstein D. Endovascular repair of aortic aneurysm in patients physically ineligible for open repair. New England Journal of Medicine. 2010; 362(20):1872-80. [PubMed: 20382982]

Wilt 2006 . Wilt TJ, Lederle FA, MacDonald R, Jonk YC, Rector TS, Kane RL. Comparison of endovascular and open surgical repairs for abdominal aortic aneurysm. Evidence Report/ Technology Assessment. 2006; 144:1-113. [PubMed: 17764213]

\section{References to other published versions of this review}

Ballard 1999 . Ballard DJ, Filardo G, Fowkes FG, Powell JT. Surgery for small asymptomatic abdominal aortic aneurysms. Cochrane Database of Systematic Reviews. 1999; (3) DOI: 10.1002/14651858.CD001835. 
Ballard 2008 . Ballard DJ, Filardo G, Fowkes G, Powell JT. Surgery for small asymptomatic abdominal aortic aneurysms. Cochrane Database of Systematic Reviews. 2008; (4) DOI: 10.1002/14651858.CD001835.pub2.

* Indicates the major publication for the study 


\section{PLAIN LANGUAGE SUMMARY}

\section{Surgery for small abdominal aortic aneurysms that do not cause symptoms}

An aneurysm is a ballooning of an artery (blood vessel), which can happen in the major artery in the abdomen (aorta). The cause is unknown. Ruptured aneurysms cause death unless surgical repair is rapid, which is difficult to achieve. Surgery for patients with aneurysms more than $5.5 \mathrm{~cm}$ in diameter or who have associated pain is considered necessary to relieve symptoms and to reduce the risk of rupture and death, although there are risks associated with surgery. Surgical repair of the aneurysm consists of insertion of a prosthetic inlay graft either by open surgery or endovascular repair.

Small asymptomatic abdominal aortic aneurysms are at low risk of rupture. They are monitored through regular imaging so they can be surgically repaired if they subsequently enlarge.

This review identified four well-conducted, controlled trials that randomised 3314 patients with small (diameter 4.0 to $5.5 \mathrm{~cm}$ ) asymptomatic aneurysms in the abdominal aorta to immediate repair or regular, routine ultrasounds to check for aneurysm growth ('surveillance'). Among the patients randomised to surveillance, the aneurysm was repaired if it was enlarging, reached $5.5 \mathrm{~cm}$ in diameter, or became symptomatic The trials did not show a meaningful difference in long-term survival between immediate repair and selective surveillance over the 3 to 10 years of follow-up. The four trials showed an early survival benefit in the surveillance group because of the number of deaths within 30 days of surgery (operative mortality). Some $31 \%$ to $75 \%$ of the participants randomised to surveillance eventually had the aneurysm repaired.

The results from the four trials conducted to date suggest no overall advantage to early surgery for small abdominal aortic aneurysms $(4.0$ to $5.5 \mathrm{~cm}$ ). The findings do not allow additional guidance for 'best-care' management of subgroups of patients (based, for example, on age, gender, or aneurysm diameter) since the trials did not provide data allowing analysis of results in these subgroups. This is in relation to the intervention versus control and the specified end-points. Furthermore, the more recent trials focused on the efficacy of endovascular aneurysm repair and still failed to show a benefit. Thus, both open and endovascular repair of small abdominal aortic aneurysms are not supported by currently available evidence. 


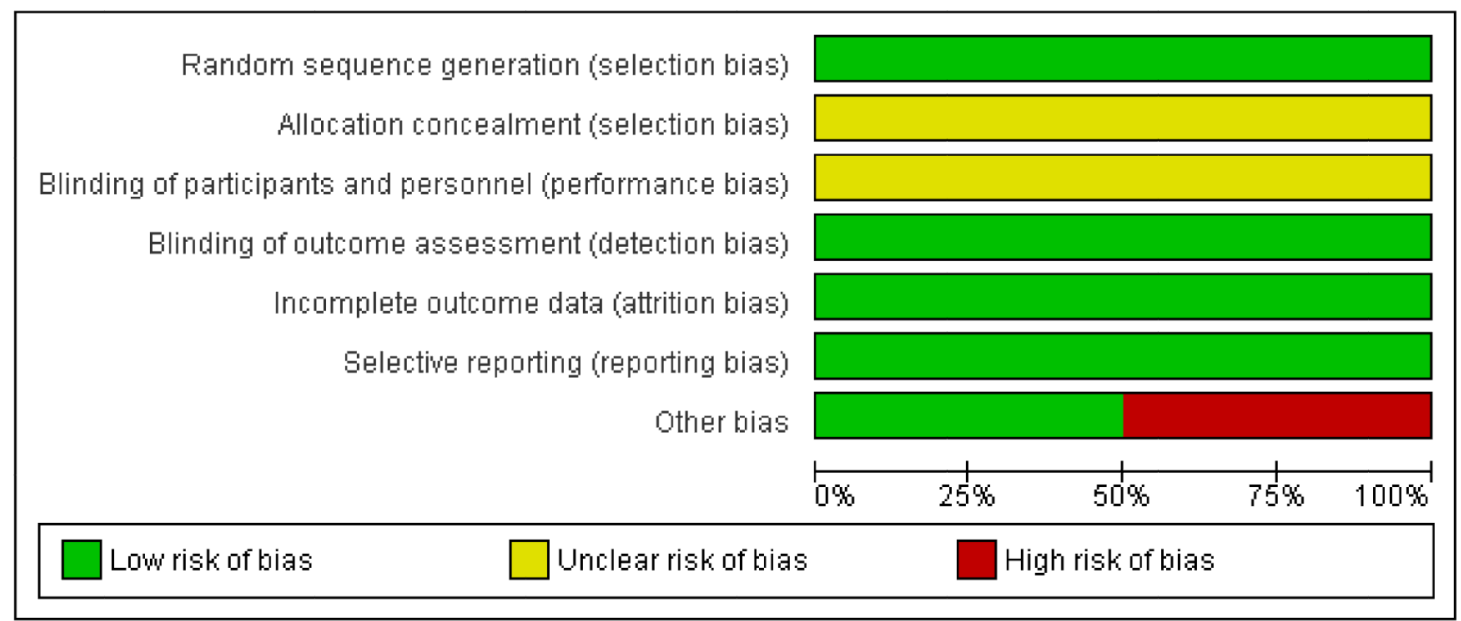

Figure 1. Risk of bias graph: review authors' judgements about each risk of bias item presented as percentages across all included studies 


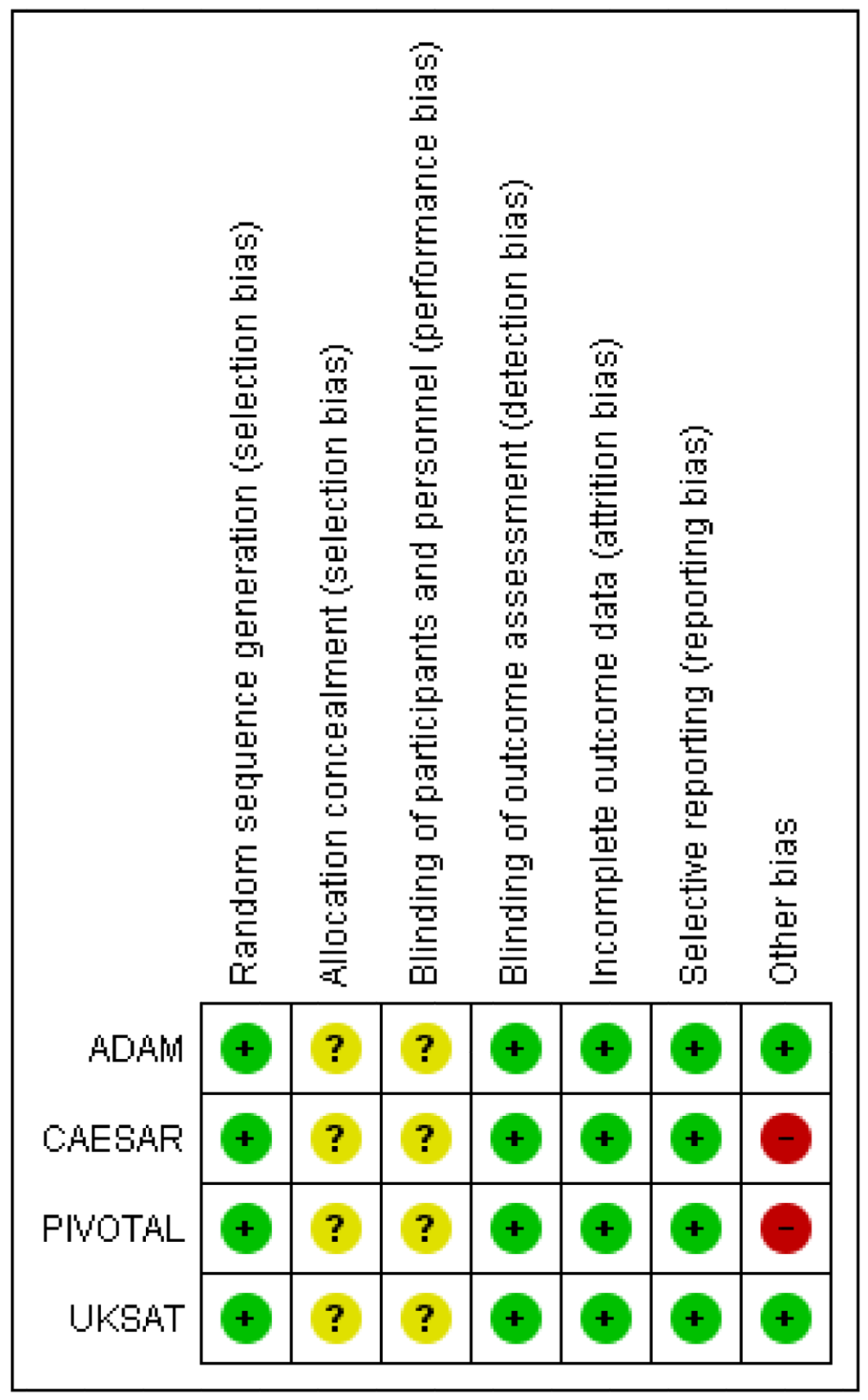

Figure 2. Risk of bias summary: review authors' judgements about each risk of bias item for each included study 


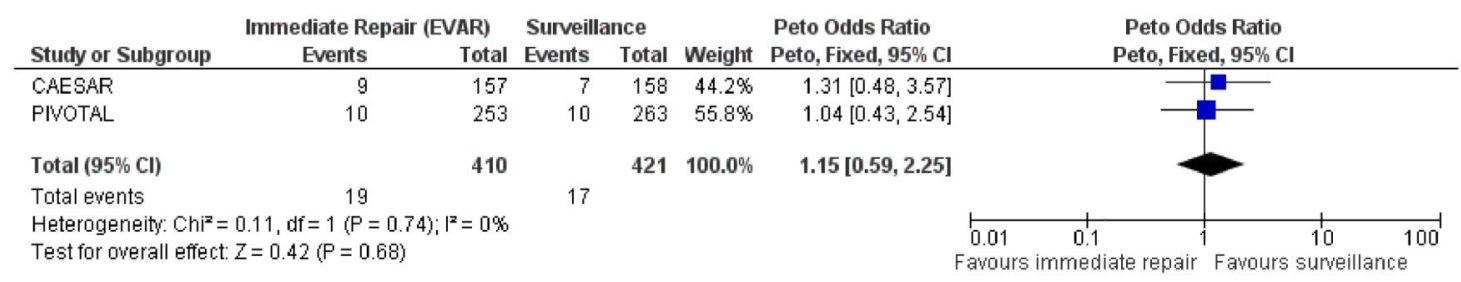

Figure 3. Forest plot of comparison: Immediate repair (EVAR) versus ultrasound surveillance at one year, outcome: 1.1 Mortality 


\begin{tabular}{|c|c|c|c|c|c|c|c|c|c|c|}
\hline \multirow[b]{2}{*}{ Study or Subgroup } & \multicolumn{2}{|c|}{ Immediate Repair } & \multicolumn{2}{|c|}{ Surveillance } & \multirow[b]{2}{*}{ Weight } & \multirow{2}{*}{$\begin{array}{l}\text { Peto Odds Ratio } \\
\text { Peto, Fixed, } 95 \% \mathrm{Cl}\end{array}$} & \multirow{2}{*}{\multicolumn{3}{|c|}{$\begin{array}{c}\text { Peto Odds Ratio } \\
\text { Peto, Fixed, } 95 \% \mathrm{Cl}\end{array}$}} & \\
\hline & Events & Total & Events & Total & & & & & & \\
\hline ADAM & 24 & 569 & 15 & 567 & $33.7 \%$ & $1.61[0.85,3.04]$ & & & & \\
\hline UKSAT & 50 & 563 & 30 & 527 & $66.3 \%$ & $1.60[1.01,2.52]$ & & & & \\
\hline Total $(95 \% \mathrm{Cl})$ & & 1132 & & 1094 & $100.0 \%$ & $1.60[1.10,2.32]$ & & & & \\
\hline Total events & 74 & & 45 & & & & & & & \\
\hline $\begin{array}{l}\text { Heterogeneity: } \mathrm{Ch}^{\mathrm{z}}= \\
\text { Test for overall effec }\end{array}$ & $\begin{array}{l}0.00, \mathrm{df}=1 \\
Z=2.49(\mathrm{P}\end{array}$ & 0.99); & $P^{2}=0 \%$ & & & & $\begin{array}{rr}0.1 & 0.2 \\
\text { Favours im }\end{array}$ & 0.51 & $\begin{array}{r}1 \\
r \text { Favours }\end{array}$ & $5^{5} 10$ \\
\hline
\end{tabular}

Figure 4. Forest plot of comparison: Immediate repair (open surgery) versus ultrasound surveillance at one year, outcome: 2.1 Mortality 


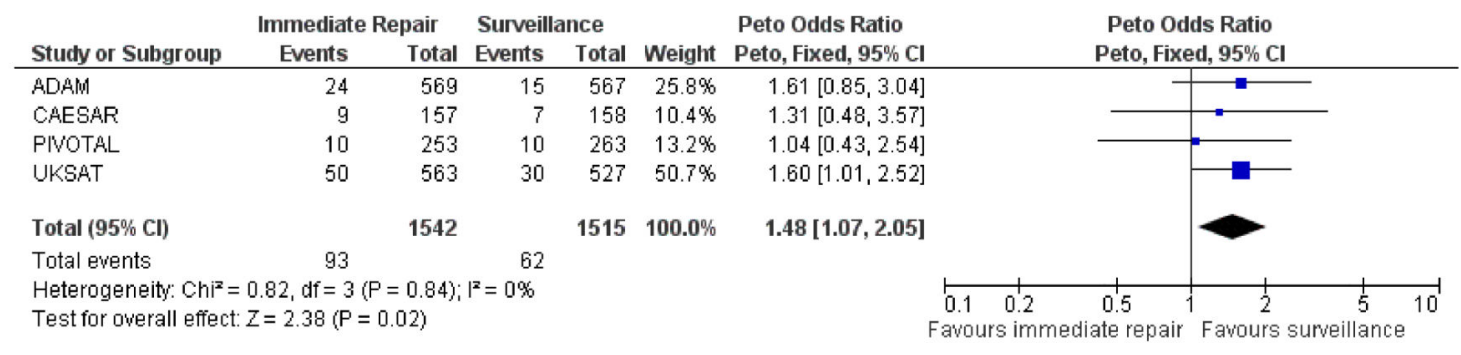

Figure 5. Forest plot of comparison: Immediate repair (either EVAR or open surgery) versus ultrasound surveillance at one year, outcome: 3.1 Mortality 


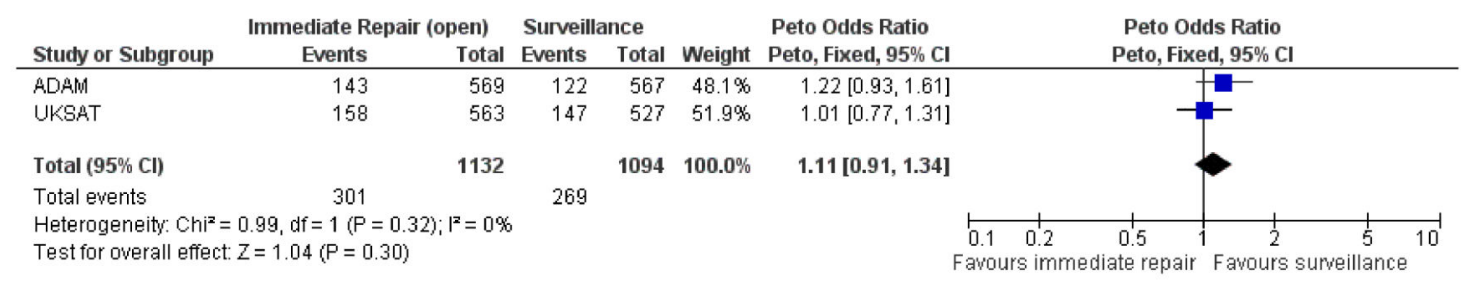

Figure 6. Forest plot of comparison: Immediate repair (open surgery) versus ultrasound surveillance at six years, outcome: 4.1 Mortality 